\title{
$O$ conceito de pessoa e a metafísica da unidade africana
}

\author{
Flaviano Lourenço Kambalu
}

RESUMO: A vocação à unidade é uma característica natural da pessoa humana porquanto esta é essencialmente livre, relacional e dialogante. A África é um complexo e heterogéneo mosaico de povos, línguas, raças, culturas, etnias e religiões, cujo fundamento metafísico de origem representa uma unidade indivisível na realidade histórica. O fundamento metafísico de origem é importante porquanto em todos os campos tudo o que une os seres humanos é mais forte do que o que os separa. Nisto, o diálogo é necessário para superar os preconceitos e desentendimentos históricos, as divisões, intolerâncias e fundamentalismos que, infelizmente, se vão intensificando na actualidade. O diálogo, conducente à unidade, não obriga, mas se move no respeito da liberdade da pessoa e da soberania de cada Estado. Enfim, trata-se de um diálogo sincero e fecundo que reconhecendo toda a legítima diversidade promove o respeito, a concórdia e a colaboração.

Palavras-chave: Pessoa humana. África. Fundamento metafísico. Fundamento Metafísico e Diálogo.

${ }^{1}$ Doutor em filosofia. Religioso saletino e Decano da faculdade de Direito da Universidade Katiavala Bwila, Benguela - Angola. E-mail: fundileko@hotmail.com. 


\section{Premissa}

No actual contexto de crescente e incisiva globalização é difícil subtrair-se ao dever ou à necessidade de prestar conta de si mesmos. Neste clima cultural também a unidade africana é chamada a justificar-se, ou seja, a justificar o seu direito de continuar a ser. À primeira vista poderia parecer que a sua justificação não seja hoje um problema, visto que é cada vez mais difuso o uso do termo unidade e da expressão união africana. Mas urge reflectir nesta unidade à luz da filosofia para lhe compreender o seu verdadeiro significado.

Aprendemos com Nicola Abbagnano que «nada do que é humano é estranho à filosofia [...] aliás esta é o mesmo homem que se interroga a si mesmo e procura as razões e o fundamento do seu ser». ${ }^{2}$ Esta é a filosofia na sua adesão à existência humana e ao mesmo tempo na sua amplitude em relação aos problemas do homem. Não dum homem que vive no úrano mas do homem concreto que na sua vida experimenta ânsias e insuficiências, alegrias e esperanças, tristezas e angústias. ${ }^{3}$ Portanto, todas as coisas são susceptíveis de reflexão filosófica, inclusive a própria unidade africana exige filosofar.

De facto, filosofar é examinar a realidade, e isso, de um modo ou de outro, todos fazemos constantemente. Ao se tentar resolver os problemas globais, sociais ou pessoais, é impossível se abster da racionalidade. Entretanto há uma gama de situações onde a razão não pode avançar por falta, ou excesso de dados, o que impossibilita decisões objectivas. Entre em cena então a parte subjectiva humana, mais especificamente a Intuição, como meio de direccionar nosso foco de entendimento e apontar caminhos a serem trilhados pela racionalidade.

\footnotetext{
${ }^{2}$ N. ABBAGNANO, Storia della filosofia I, UTET, Torino 1963, p. XVII. ${ }^{3}$ Cf. CONCÍLIO VATICANO II, Gaudium et Spes, n. 1.
} 
Só que, actualmente, a filosofia passa por uma perda de identidade. Existe uma verdadeira inflação do termo filosofia e, como toda a inflação, é sintoma de queda de valores, de crise difusa e profunda. Hoje o termo filosofia indica muitas vezes coisas difíceis, próprias do hiperurâneo e não o homem que, não aceitando passivamente as informações fornecidas pela experiência imediata, desenvolve uma postura de questionamento próprio sobre a realidade, interroga-se a si mesmo e metodológica e ordenadamente procura as razões e o fundamento do seu ser, buscando, como faziam os gregos, um instrumento fundamental e o único racionalmente possível, para a solução dos problemas da vida.

A confusão com relação à filosofia, e a desinformação geral, que permeia mesmo o meio académico, chega a ponto de permitir o surgimento de propostas quiméricas no sentido de se eliminar a Filosofia. Entretanto, ciência alguma pode se ocupar da macro realidade. $\mathrm{O}$ empirismo não pode ser aplicado à civilização humana, à mente, ao total. Quem estabelece a comunicação entre todos os segmentos do conhecimento continua a ser a filosofia. Cremos ser este o quadro em que se deve inserir a reflexão sobre a unidade africana, que aqui fazemos partindo da metafísica do termo pessoa.

Tal reflexão se torna urgente sobretudo se olharmos para os problemas que cada vez mais vão desafiando a unidade do continente africano. Há uma verdade, hoje admitida por quase todos e até pelos mais preconceituosos arqueólogos, de que a humanidade e a civilização desenvolveram-se na noite dos tempos no berço deste continente gigantesco chamado África ${ }^{3}$.

Temos consciência de que a África é um imenso continente com situações muito diversas; um complexo e heterogéneo mosaico de povos, línguas, raças, culturas, etnias e religiões, mesmo dentro das mesmas fronteiras políticas. Embora esta imensidão nos

\footnotetext{
${ }^{3}$ Cf. Carlos SERRANO - Maurício WALDMAN, Memória d'África. A temática africana em sala de aula, Cortez Editora, São Paulo $2008^{2}$, p. 75. Cf. Também, Luigi TRANFO, Africa. La transizione. Tra sfruttamento e indifferenza, E.M.I., Bologna 1995, p. 269; Pedro F. MIGUEL, África. Uma visão global, Viverein, Roma 2013, p. 11.
} 
aconselhe a não fazer generalizações na avaliação dos problemas não nos impede de buscar e propor soluções aos problemas inerentes à falta de unidade que a nosso ver pode podem assentar sobre o conceito de pessoa.

\section{Breve excursus histórico-filosófico do conceito de pessoa}

\subsection{A densidade semântico-etimológica do termo pessoa}

A densidade semântica do termo pessoa formou-se no tempo graças ao contributo cultural de muitos filões de reflexão. O conceito de pessoa tem, pois, um percurso rico, quanto complexo.

De recordar que na antiguidade greco-romana não se encontra bem claro o conceito de pessoa. Todavia, seria incorrecto pensar que o conceito de pessoa tenha nascido nos nossos dias.

Etimologicamente, e segundo algumas pesquisas atentas, os primeiros indícios do termo pessoa encontram-se no âmbito da cultura etrusca. De facto, o termo phersu, utilizado nos ritos em honra de Phersepona e que significaria máscara ${ }^{4}$ passou a significar o indivíduo mascarado, a personagem que o actor representa no drama, ou seja, o indivíduo humano, moral e social ${ }^{5}$.

Nesta senda do indivíduo mascarado, Edith Stein observa que visto que nas comédias e nas tragédias se representavam personagens famosos, o nome pessoa foi imposto para significar sujeitos que tinham um papel na sociedade, por isso, alguns definem a pessoa como «uma hipóstase marcada por uma qualificada conexão com a sua dignidade» ${ }^{6}$.

\footnotetext{
${ }^{4}$ Cf. Maurice NÉDONCELLE, Prosopon et persona dans l'antiquité classique. Essai de bilan linguistique, in «Revue des sciences religieuses» XXII (1948) 277-299; A. MILANO, Persona in teologia, Dehoniane, Napoli 1984, pp. 16-71.

${ }^{5}$ Cf. Maurice NÉDONCELLE, Prosopon et persona dans l'antiquité classique. Essai de bilan linguistique, op. cit., pp. 298-299.

${ }^{6}$ Edith STEIN, Essere finito e essere eterno. Per una elevavazione al senso dell'essere, Città Nuova, Roma 1988, p. 380.
} 
Não encontra fundamento adequado a etimologia proposta por Boécio, que liga pessoa ao verbo personare, aludindo à amplificação da voz de quem fala por detrás da máscara. Assim, pessoa é, segundo Boécio, «decta est volvatur sonus» ${ }^{6}$. Também não é correcto afirmar que pessoa seja a contracção de per se una, como quereria a proposta de Alano di Lilla?.

\subsection{O percurso evolutivo do conceito de pessoa}

Com Cícero e Séneca, a evolução do conceito de pessoa deu passos importantes sem, contudo, chegar à definição hodierna.

Do segundo século em diante, o conceito de pessoa entra no uso corrente, na onda do esforço de clarificação exigida pelas controvérsias teológicas sobre o dogma trinitário. Porém, foi com Boécio que o conceito de pessoa adquire o actual conteúdo teórico. E isto no contexto da clarificação conceitual sobre as questões teoréticas que emergiam da doutrina sobre a Trindade.

Segundo Boécio «persona est rationalis naturae individua substantia» (pessoa é substância individual de natureza racional) ${ }^{8}$. Boécio elabora esta definição, servindo-se do património filosófico grego e latino. De facto, ele sistematiza os conceitos latinos de persona, natura e substantia, estabelecendo uma equivalência com

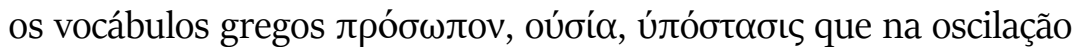
terminológica do tempo eram usados de maneira equívoca e confusa.

Com Boécio, a natura toma definitivamente o lugar de oúøí $\alpha$, entendida como essência, e substantia passa a traduzir o grego

\footnotetext{
${ }^{6}$ S. BOEZIO, Liber de duabus naturis, III; PL 64, 1344.

${ }^{7}$ Cf. Enrico BERTI, Il concetto di persona nella storia del pensiero filosofico, in AA.VV., Persona e personalismo. Aspetti filosofici e teologici, Fondazione Lanza, Padova 1992, p. 43.

${ }^{8}$ S. BOEZIO, Liber de duabus naturis, III; PL 64, 1343.
} 


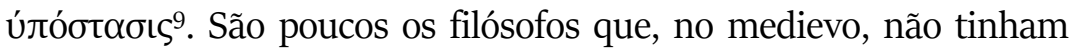
encontrado a definição de Boécio satisfatória, porque essa interpretava a realidade que se tentava definir, precisando-lhe o significado.

Esta definição, pessoa é substância individual de natureza racional que, durante o medievo, faz cultura e caracteriza a tradição teológica latina, surge sob o impulso das disputas contra os nestorianos, os quais sustentavam que, em Cristo havia duas naturezas e duas pessoas em união permanente e moral; e contra os monofisistas que sustentavam a existência em Cristo de uma só natureza, a divina ${ }^{10}$.

Na definição de Boécio, o termo pessoa tem um sentido mais específico e se refere à estrutura fundamental e metafísica do indivíduo, ou seja, à substância individual dotada de uma natureza racional. Quer dizer, nem todos os seres naturais são pessoas, mas apenas aqueles substanciais.

Por isso, a pessoa é substância individual. É individual porque tem características que a distinguem dos outros indivíduos da mesma espécie; características que não são definíveis nem comunicáveis aos outros. É substância porque é existente em si, por si e em nenhum outro. Dizer substância individual significa, portanto, dizer que a pessoa não tem necessidade, para existir, de

\footnotetext{
9 Cf. Claudio MICAELLI, "Natura" e "Persona" nel "Contra Eutychen et Nestorium" di Boezio: Osservazioni su alcuni problemi filosofici e linguistici, in Luca OBERTELLO (a cura di), Atti del Congresso Internazionale di Studi Boeziani (Pavia 5-8 ott. 1980), Herder, Roma 1981, p. 336.

${ }^{10}$ Fruto destas disputas é a obra de Boécio Liber de persona et duabus naturis contra Eutychen et Nestorium, cujo objectivo imediato foi aquele de combater as heresias de Eutique e Nestório. De recordar, porém, que desde os primeiros séculos do cristianismo o conceito de pessoa oferece grande importância -com Tertuliano, os Padres Capadócios, S. Agostinho e S. João Damasceno - nos interrogativos teoréticos que emergiam da Revelação e nas controvérsias teológicas acerca do dogma trinitário. Tais controvérsias se concluíram com a fórmula das três pessoas ou hipóstases na única substância, oúøí $\alpha$ ou natureza divina. Os Padres da Igreja, separando de maneira definitiva o conceito de $\pi \rho \sigma \sigma \omega \pi$ da $^{\text {da referencia à personagem }}$ trágica ou cómica, deram fôlego a um aprofundamento do conceito de pessoa também na reflexão filosófica (cf. Gregorio DI NISSA, La grande catechesi, CIttà Nuova, Roma 1982, p. 51; Gregorio NAZIANZENO, I cinque discorsi teologici, CIttà Nuova, Roma 1986, p. 175).
} 
aderir a um outro ser, e contém no seu quid alguma coisa de incomunicabilidade, que divide com nenhum outro ${ }^{11}$.

A pessoa é igualmente de natureza racional. O seu conhecer não é impresso na matéria, nem é limitado por essa. Dizer natureza racional significa, por isso, que a pessoa não só exerce as actividades conexas à natureza, mas tem a capacidade de desenvolvê-las, capacidade possuída por natureza, ou seja com o nascimento ${ }^{12}$. A pessoa é, pois, o gau mais elevado de ser substancial, porque essa é consciente do seu ser substância individual.

Toda a pessoa é, portanto, antes de mais um indivíduo. Mas ao mesmo tempo, muito mais que indivíduo, porque não é uma personagem, mas uma substância individual, que possui em si uma certa dignidade em razão da sua racionalidade. Por isso, não basta afirmar que a pessoa é algo de individual e nem mesmo que é uma substância ou uma natureza, para defini-la do ponto de vista metafísico.

Visto que a individualidade é acidente, isto é, pertence àquilo que existe como perfeição e é característica de um sujeito, e enquanto a substância e a natureza indicam o que é próprio da espécie, ocorre a substância individual de uma natureza racional, para que exista pessoa. Ocorre, portanto, que se refira a uma substância individualizada de um ser racional, para que exista pessoa do ponto de vista metafísico. Somente um ser racional pode corresponder à dignidade de pessoa, porque pessoa é, enfim, um ser em si, que não pode ser substituído por um outro e que é capaz de operações próprias e racionais.

Revisitando o pensamento precedente e partindo do esquema e da fórmula de Boécio, São Tomás elabora a sua definição de pessoa como «subsistens in rationali natura» ${ }^{13}$.

\footnotetext{
${ }^{11}$ Cf. San Tommaso D'AQUINO, Questiones disputatae, De potentia, q. 9, a. 2; ID., Summa Theologiae, I, q. 29, a.

${ }^{12}$ Cf. E. BERTI, Il concetto di persona nella storia del pensiero filosofico, op. cit., p. 48.

${ }^{13}$ Cf. S. Tommaso D'AQUINO, Summa Theologiae, I, q. 29, a. 3. c.
} 
Com a fórmula subsistens in rationali natura, São Tomás evidencia não só o aspecto comum - pressuposto universalmente aceite da pessoa - assim como expresso pela substância individual da definição de Boécio, mas evidencia sobretudo aquele individual, isto é, o existente considerado na acepção mais própria, ou seja o seu ser único e irrepetível. De facto, nela definição de Boécio a substância individual, parece ser concebida como individualidade. A individualidade, porém, é determinação da coisa e não ainda do quem; é uma conotação natural da pessoa e não da mesma pessoa.

São Tomás condensa o conceito de pessoa nos termos subsistente e racional para indicar o que de mais nobre e perfeito há no universo; e por isso afirma: "persona significat id quod est perfectissimum in tota natura, scilicet subsistens in rationali natura» ${ }^{14}$.

Pessoa é a natureza racional que existe num indivíduo concreto. Por isso, somente aquilo que é subsistente numa natureza racional pode ser chamado pessoa. E é o subsistir de maneira individual na natureza racional que confere a dignidade à pessoa, ou seja, «quia magnae dignitatis est in rationali natura subsistens ideo omne individuum rationalis naturae dicitur persona» ${ }^{15}$.

De tudo isto emerge que a nobreza da pessoa humana não é a abstracta razão - como parece indicar a natureza racional da definição de Boécio - mas a racionalidade possuída por um subsistente, ou seja, de um ser concreto. E este em virtude de um actus essendi próprio, que confere actualidade à substância e às suas determinações. Tudo isto que a pessoa sabe, quer e faz, brota do próprio acto em virtude do qual é aquilo que é.

Da elaboração de São Tomás se compreende essencialmente o carácter racional da pessoa; racional enquanto capaz de ser consciente do próprio $\operatorname{ser}^{16}$. A pessoa é todo o indivíduo de natureza

\footnotetext{
${ }^{14}$ Ibidem.

${ }^{15}$ Ibidem.

${ }^{16}$ Muitas vezes o termo racional é confuso com o termo intelectual. Na verdade intelecto e razão diferem. O intelectual é um conhecimento simples e imediato, enquanto o racional passa de um
} 
racional, livre, atravessado por tradições e culturas, responsável, relacional, inteligente, volitivo, dialogante e por isso, fundamento de unidade entre indivíduos e povos.

\section{Do conceito da pessoa à construção da unidade africana}

Antes da conquista das independências os colonos procuravam inflamar as diferenças fechando as colónias em si mesmas, num clima de reserva ciumenta, de distância e quase de desconfiança. Com as independências os encontros entre países antigamente colonizados se multiplicaram e o clima tornou-se de abertura e de colaboração. E com a criação da OUA, que veio a desempenhar o papel extremamente precioso de lugar de encontros, de órgão de diálogo e de troca de experiências entre Chefes de Estado e de Governo africanos, o esforço para a unidade se exprimiu de modo mais visível.

Contudo, a vocação à unidade é uma característica natural da pessoa humana porquanto esta é essencialmente livre, relacional e dialogante. E enquanto essencialmente relacionais e dialogantes existem nos homens aqueles elementos comuns que constituem a sua natureza e que os distinguem das outras espécies de seres. Todos os homens têm as mesmas tendências e exigências fundamentais quanto ao anélito da unidade. Todo o homem é chamado à comunhão e está aberto à comunicação e ao diálogo.

O homem é capaz, pois, de intercâmbio, de dar-se aos outros e deles receber, porque a sua natureza o abre à comunhão, à comunicação e à unidade. A sua natureza relacional e dialogante não é apenas uma necessidade mas é sobretudo um dom que o ambiente que o impede de continuar fechado e isolado no egoísmo e aberto aos conflitos. De facto, o homem é aquilo que é pela sua inconfundível individualidade, mas também pelo seu ser aberto ao

conhecimento simples para um mais complexo (cf. S. Tommaso D’AQUINO, Summa Theologiae, I, q. 59, a. 1). 
outro e às realidades extrínsecas, por causa da sua sociabilidade. A sociabilidade é, pois, uma expressão da sua humanidade, e a unidade, uma sua actuação.

Por isso, a unidade africana pressupõe a união consciente entre africanos, e o comum e orgânico esforço, para conseguir o bem humano integral. A unidade africana, na base da descoberta da comum humanidade, articula-se na corresponsabilidade generosa de todos para com todos, e em cada povo africano tomar sobre si as dificuldades e os problemas dos outros povos do continente para alcançar o bem comum ${ }^{17}$.

Enfim, a unidade encontra a sua raiz na essência metafísica da pessoa humana e exprime, por conseguinte a estrutura ontológica dos africanos e diz respeito à própria possibilidade da sua realização. Por isso, as divisões e os conflitos lupescos não fazem parte da normalidade africana.

Portanto, apesar de a África ser um imenso continente com situações muito diversas; um complexo e heterogéneo mosaico de povos, línguas, raças, culturas, etnias e religiões, mesmo dentro das mesmas fronteiras políticas, o continente africano se explica como unidade na diversidade. E enquanto africanos reconhecemos que a unidade nos é garantida metafisicamente pela origem, pelo facto mesmo de sermos africanos - do Cabo ao Cairo, de Dar es-Salaam a Dakar - mas sobretudo pelo facto de sermos pessoas humanas.

O fundamento metafísico de origem representa uma unidade indivisível na realidade histórica, uma força inspiradora e enriquecedora para os africanos que pode mesmo superar as diversidades presentes nos Estados africanos, a incomunicabilidade geográfica, a hipocrisia, as tensões e os desejos separatistas, e conduzir a um compromisso claro entre os africanos, respeitando as suas diversidades e os seus interesses recíprocos; empenhando num projecto comum para uma África mais humana e mais social, em

${ }^{17}$ Cf. L. F. KAMBALU, A democracia personalista. Os fundamentos onto-antropológicos da política à luz de Pietro Pavan, Paulinas, Lisboa 2012, pp. 51-64. 
que reinem sempre o respeito mútuo, o reconhecimento e a protecção dos direitos humanos fundamentais e se faça valer o lado melhor dos africanos, os valores basilares da paz, da justiça, da liberdade, da tolerância, da participação e da solidariedade. Este fundamento metafísico de origem é importante porquanto em todos os campos tudo o que une os seres humanos é mais forte do que o que os separa.

Contudo, a unidade africana deve ser construída e aprofundada de forma dinâmica e incessante, porque os pressupostos da união, representados pelos factores geográficos; pela multiplicidade das tradições regionais, nacionais, culturais e religiosas; pelos interesses económicos, trocas económicas pacíficas e seguras; pela herança e tradições socioculturais africanas mais autênticas, em si não bastam para criar a união política. É necessário voltarmos à metafísica da unidade e reelaborar juntos a história da África que além das muito boas experiências de unidade é ainda caracterizada, nalguns casos, por desentendimentos, lutas fratricidas entre etnias e até por conflitos bélicos.

Com razão, Kwame Nkrumah, apelava, na sua obra A África deve unir-se, à unidade, não tanto para indicar a necessidade ou condição de estar unidos, mas sobretudo o acto de se unir porque os pressupostos geográficos e económicos, por si só, não bastam para criar a união. Ocorrem instituições vinculativas bem como vontade e consciência de pertença, a um mesmo continente chamado África. A consciência deve preceder à formação política da unidade africana que não se poderá alcançar de forma duradoira sem valores comuns. Outrossim, ocorre recordar que a unidade é em si um bem somente quando é ordenada, quando responde à razão objectiva da verdade, da justiça e do bem. O mesmo é dizer que a unidade é um bem que vale tanto quanto respeita o que há de valor nas partes que a compõem.

A unidade perde valor quando se realiza de modo maciço, esmagador, absoluto, destruidor e totalitário abolindo o espaço que permite o diálogo, destruindo desta forma a esfera em que os 
homens agem, tomam decisões comuns e operam colaborando. Por isso, sem liberdade nem diálogo a unidade africana seria impossível porque a África não seria mais o espaço onde cada indivíduo aos outros as próprias capacidades em vista do bem comum, segundo princípios de igualdade substancial. Neste sentido a África seria um conjunto de indivíduos e por conseguinte um conjunto de Estados sem laços entre si. Cada um veria o outro não como um semelhante, com quem é chamado a relacionar-se e tomar iniciativas, mas um inimigo de quem se defender.

Enfim, para reconstruir a unidade africana deve-se partir da pessoa humana e ocorre uma política que envolva todas as pessoas e forças a todos os níveis na busca do bem comum, ou seja, na busca daquele conjunto de elementos essenciais que respondem às exigências intrínsecas e imutáveis da natureza humana. Trata-se, pois, de condições económicas, jurídicas, morais e religiosas que tornam possível e favorecem o conseguimento pleno e fácil do desenvolvimento integral das pessoas.

As exigências históricas e os significados de unidade são sempre mutáveis. Mudam conforme se entenda o que leva os homens a unirem-se, a nível ontológico e histórico, ou seja, consoante a efectiva existência daquele princípio originário em cada homem e povo ou consoante o plano social, político, religioso e cultural em que se actua a unidade. De facto, não poucas vezes, os próprios acontecimentos históricos e as próprias diferenças exigem que se redefinam os instrumentos políticos para construir uma nova ordem inspirada numa nova filosofia de relações entre povos e Estados, que vão além do que no passado não foi possível. Tais diferenças podem provir de uma profunda oposição e de uma divergência quanto ao fim. As diferenças podem provir também de uma dupla visão de um mesmo objectivo. Seja qual for a origem das diferenças a atitude sadia é compreender as realidades e promover o diálogo e ver como as próprias diferenças permitem situar melhor o objecto. 
Por isso, é mister que nos diversos âmbitos, questões e temas sobre os quais incumbe o risco da divisão, os africanos usem a mesma linguagem e falem a uma só voz, cultivando e empenhandose intensa, livre e conscientemente ao diálogo.

O diálogo é fundamental para a vida política sobretudo quando exerce a função da busca da verdade e do bem. No caso da África o diálogo torna-se uma exigência insubstituível para superar as divisões, intolerâncias e fundamentalismos que, infelizmente, se vão intensificando na actualidade. $\mathrm{O}$ diálogo é igualmente fundamental para superar os preconceitos e desentendimentos históricos, culturais, raciais, sociais e religiosos e promover e concretizar a unidade, a justiça e a paz, não só por causa do pluralismo étnico, cultural, racial, social e religioso do continente, mas sobretudo por causa do seu pluralismo político, pois, através do diálogo cada indivíduo ou povo enriquece o próprio ponto de vista e converge para as noções de verdade e de bem humano e se empenha a potenciá-las corresponsavelmente para a unidade.

O diálogo é também essencial para a unidade política, social e económica e o desenvolvimento integral dos povos e dos Estados africanos, pois, tal como os povos também os Estados têm necessidade uns dos outros para se encontrarem a si próprios e no encontro com os outros se realizarem plenamente. Por isso, o isolamento seria um impedimento insuperável para a unidade e a realização do próprio continente africano.

Tal diálogo deve basear-se em valores, princípios e normas aceites, e deve ser assegurada por um sistema constitucional e de direito; pela promoção da justiça, da paz e da liberdade para o continente africano; pela experiência da verdade e pela busca constante de compreensão dos fundamentos que têm plasmado a União Africana.

O diálogo não se processa sem dificuldades e é alcançável através da discussão e argumentação; é reconhecível por todos a partir de um comum confronto que se funda sobre a dignidade pessoa humana e é possível a diversos níveis: no plano da 
experiência quotidiana para as questões sociais, comunitárias, familiares, éticas e ecológicas; no plano do encontro das culturas para o respeito e o melhor conhecimento recíproco; no plano desportivo para o cultivo do sentimento de pertença a um todo continental; no plano político para questões que dizem respeito à segurança económica, cultural e jurídica; no plano militar para questões que dizem respeito à garantia da segurança e integridade territorial bem como à erradicação de conflitos em África.

Trata-se de um diálogo gradual e sempre pronto a recomeçar. Um diálogo que não obriga, mas se move no respeito da liberdade pessoal e civil e da soberania de cada Estado; trata-se de um diálogo que não é apenas instrumental nem nasce de tácticas ou de interesses, mas um diálogo sincero e fecundo que reconhecendo toda a legítima diversidade promove o respeito, a concórdia e a colaboração.

Enfim, trata-se de uma actividade que apresenta motivações, exigências e dignidade própria e implica um mútuo esforço de compreensão por parte dos interlocutores que se compreendem verdadeiramente quando descobrem, além dos laços que os unem e os integram uns aos outros e dos valores a eles comuns, as razões ideais em que cada um deles se inspira para realizá-los.

Outrossim, tal diálogo destina-se a produzir efeitos extraordinariamente benéficos, como o aumento da maturidade dos africanos - numa penetração mais autêntica da complexa realidade do mundo hodierno em que a África se move - a resolução dos problemas, a superação dos desafios relacionados com a unidade e a luta pela prosperidade e felicidade de todas as nações bem como pela segurança e bem-estar do continente africano.

Tudo isso levanta muitos e difíceis problemas de ordem económica, social e política. Porém, está de facto que diante das diferenças e dos antagonismos que o continente africano vive actualmente, só a consciência da comum humanidade e o diálogo franco, lúcido e proveitoso pode permitir construir um caminho de tolerância e aceitação mútuas para a realização de uma convivência 
respeitosa e articulada na reciprocidade sobre o fundamento da dignidade da pessoa humana, da mobilidade interna, da integração sócio-económica do continente e do florescimento de um mercado interno. Isto fará também com que os africanos não sejam meros fornecedores de matérias-primas aos outros continentes e consumidores de produtos estrangeiros, mas produtores e consumidores de produtos do seu próprio continente.

Um diálogo não inibido por complexos de superioridade ou de inferioridade, mas um diálogo franco na base da consciência de pessoas humanas e do respeito recíproco. De facto, sem diálogo franco não há progresso porquanto o progresso é liberdade, e somente a verdade que pode exprimir-se nos torna livres.

\section{Referências}

ABBAGNANO, Nicola, Storia della filosofia I, UTET, Torino 1963.

BERTI, Enrico, Il concetto di persona nella storia del pensiero filosofico, in AA.VV., Persona e personalismo. Aspetti filosofici e teologici, Fondazione Lanza, Padova 1992.

DI NISSA, Gregorio La grande catechesi, CIttà Nuova, Roma 1982.

ELUNGU, P. E. A., Eveil philosophique africain, Éditions L'Hartmattan, Paris 1984 .

KAMBALU, Lourenço Flaviano, A democracia personalista. Os fundamentos ontoantropológicos da política à luz de Pietro Pavan, Paulinas, Lisboa 2012.

MICAELLI, Claudio, "Natura" e "Persona" nel "Contra Eutychen et Nestorium" di Boezio: Osservazioni su alcuni problemi filosofici e linguistici, in Luca OBERTELLO (a cura di), Atti del Congresso Internazionale di Studi Boeziani (Pavia 5-8 ott. 1980), Herder, Roma 1981.

MIGUEL, Pedro F., África. Uma visão global, Viverein, Roma 2013

MONDIN, Battista, Introdução à filosofia. Problemas, sistemas, autores, obras, Paulus, São Paulo $2007^{14}$. 
42 | Revista Opinião Filosófica, Porto Alegre, V. o9; No. 01, 2018

,Curso de filosofia. Os filósofos do Ocidente, vol.I, Paulus, São Paulo $2007^{14}$.

NAZIANZENO, Gregorio, I cinque discorsi teologici, CIttà Nuova, Roma 1986.

NÉDONCELLE, Maurice, Prosopon et persona dans l'antiquité classique. Essai de bilan linguistique, in «Revue des sciences religieuses» XXII (1948) 277299; A. MILANO, Persona in teologia, Dehoniane, Napoli 1984

PANNIKKAR, Raimondo, Il messaggio dell'India di ieri al mondo di oggi, in «Filosofia», n. 22, 1971, pp. 3-10.

REALE Giovanni - ANTISERI, Dario, Il pensiero occidentale dale origini ad oggi, vol. I, Editrice Scuola, Brescia $2000^{22}$.

RIGOBELLO, Armando, Perché la filosofia, Editrice La Scuola, Brescia $1997^{5}$.

ROVIGHI, Sofia Vanni, Elementi di filosofia, Editrice La Scuola, Brescia $1975^{5}$.

SERRANO, Carlos -WALDMAN, Maurício, Memória d'África. A temática africana em sala de aula, Cortez Editora, São Paulo $2008^{2}$.

STEIN, Edith, Essere finito e essere eterno. Per una elevavazione al senso dell'essere, Città Nuova, Roma 1988, p. 380.

TRANFO, Luigi, Africa. La transizione. Tra sfruttamento e indifferenza, E.M.I., Bologna 1995. 